\title{
Use of a floating breakwater system as an environmentally friendly method of coastal shelter
}

\author{
H. M. Teh, M. S. M. Azizan, V. J. Kurian \& A. M. Hashim \\ Civil Engineering Department, \\ University Teknologi PETRONAS, Malaysia
}

\begin{abstract}
Floating breakwaters are known as environmentally-friendly methods of coastal shelter due to the fact that they pose minimum interruption to water circulation and sediment transport. However, the majority of them are strong wave reflectors, directing wave energy to the seaward and resulting in confusing sea state at the seaward side. This research aimed to quantify the wave transmission, wave reflection and energy loss by the H-type floating breakwater via physical modelling. The performance characteristics of the breakwater were measured by the coefficient of transmission, reflection and energy loss. The coefficients were related to a dimensionless wave parameter and the relative immersion depth of breakwater. The experimental results showed that the H-type floating breakwater is a good anti-reflection structure and an effective energy dissipater. The hydraulic performance of the breakwater was more controlled by the relative breakwater immersion depth than the wave parameter.
\end{abstract}

Keywords: floating breakwaters, wave transmission, wave reflection, energy loss.

\section{Introduction}

The use of breakwaters for coastal protection is common for beaches of high commercial and recreational values. They are very often perceived as the defence structures that would save lives, properties and resources in coastal areas. The gravity-type breakwater has been the most conventional coastal defence structure that offer both wave protection and shoreline realignment. Gravity-type breakwaters are rigidly rested on the sea bottom. They are generally massive in size and heavy so as to provide ample structural strength and stability against 
destructive waves. Allsop [1] classified gravity-type breakwaters into three types based on their geometrical characteristics, namely (1) permeable rubble mound breakwaters, (2) impermeable upright or steep-face breakwaters, and (3) composite breakwaters. It is no doubt the gravity type breakwaters provide high degree of wave attenuation; nevertheless, the environmental impact they may cause might be intolerable to the sensitive sites. The detrimental effects to the coastal and marine environment include threat to marine ecosystem, water contamination during construction, uncontrolled or excessive sedimentation at upcoast and at leeside of the breakwater, and shoreline erosion at the down-coast.

Unlike fixed breakwaters, floating breakwaters are fundamentally barricade afloat at free surface where the energy flux and water particle orbital motion are maximal. They are primarily used to distort orbital motion of water particles near sea surface and to retard the transmission of waves through their structural configurations. The motion responses of floating breakwaters are literally controlled by the installation methods adopted, e.g. pile mooring, catenary mooring and taut leg mooring. For instance, the motion responses of a floating breakwater in six-degree of freedom are restricted more by the taut leg mooring compared to the catenary mooring. Thus, a floating breakwater held by taut leg mooring tends to be a more efficient wave attenuator.

In some locations where complete wave suppression is not needed, floating breakwater may be a viable alternative to the gravity-type breakwaters. The construction of floating breakwaters is economical compared to the conventional breakwater especially when constructed at sites with relatively large water depths. They can be pre-fabricated and towed to the site by floating barges for installation without imposing appreciable noise, dust and water pollutions on site. The breakwater can be easily dissembled and recycle for installation on a new site with minimum carbon emission. The construction of floating breakwater is less affected by the quality of the bottom soil condition and underwater bathymetry. Most importantly, floating breakwaters care for the marine environment by allowing water exchange, fish migration and sediment transport beneath the floating barriers. Floating breakwaters offer such desirable characteristics that allow them to be potentially used as sea defence structures in recreational harbours, marinas and fishing ports.

The control of hydraulic performance of the floating breakwater by its geometry has been widely studied by different researchers [2-4]. McCartney [5] generally classified the floating breakwaters into four types, i.e. box, pontoon, mat and tethered float. These breakwaters modify the energy of the incident waves mainly by reflection, breaking and frictional loss during wave-structure interactions. Due to the limited size of the floating breakwater compared to the conventional breakwater, they become less effective when approached by waves of more than $5 \mathrm{~s}$ and $1 \mathrm{~m} \mathrm{[6].} \mathrm{In} \mathrm{another} \mathrm{word,} \mathrm{floating} \mathrm{breakwaters} \mathrm{are} \mathrm{best} \mathrm{used}$ at semi-sheltered sites that are exposed to short period waves and the under-design breakwaters may have little survivability when confronted by extreme storm waves. The drawbacks of the floating breakwaters have limited their usage, hence they are very often used as supporting structures to the main wave defence structures $[7,8]$. 
Wave reflection in front of breakwaters is undesirable in many waterfront facilities, particularly harbours and marinas. Confusing sea states resulted by reflected waves may cause navigation hazard to small floating vessels when getting close to the seaward of the breakwater. In this study, an attempt is made to develop a floating breakwater that is potentially a good anti-reflection wave defence structure. This research aims to evaluate the performance characteristics of the proposed breakwater using physical modelling.

\section{Test model}

Figure 1 presents the model layout of the $1.00-\mathrm{m}$ wide, $1.44-\mathrm{m}$ long and $0.5-\mathrm{m}$ high H-type floating breakwater. The upward arms were designed to promote breaking of incident waves; whilst the downward legs were to induce more energy dissipation through formation of vortices and underwater diffusion. The framework of the model was made of plywood. The durability and water-proof ability of the model was attained by application of a layer of fiberglass coating at the exterior. A ballast chamber has been incorporated in the model so as to adjust the stability and immersion depth of the breakwater in water. This could be achieved by placement of sandbag in the 18-slot chamber, as shown in Figure 1. To prevent from water intrusion, the chamber was covered by a Plexiglas lid, in which all gaps were completely sealed.

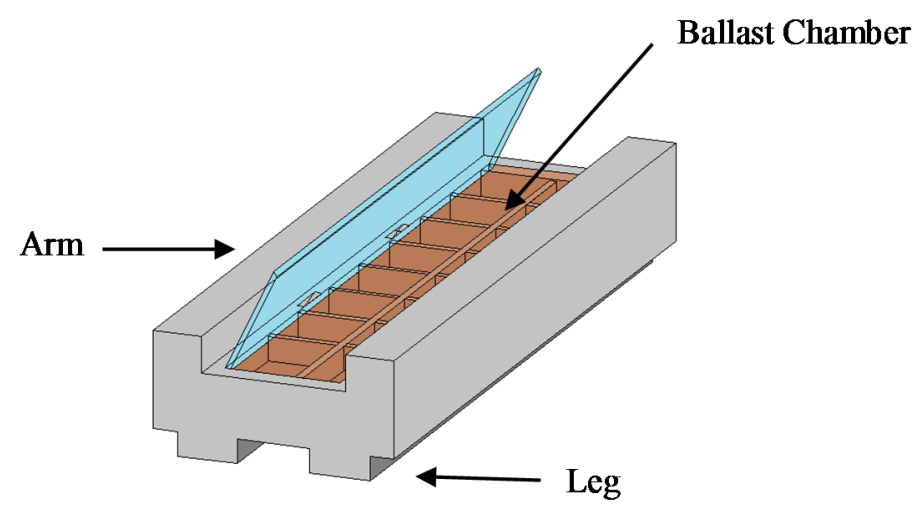

Figure 1: The H-type floating breakwater: test model.

\section{Experimental set-up and program}

In this study, experiments were conducted in a $25 \mathrm{~m}$ wave flume equipped with the flap-type, active absorption wave generatorat the Offshore Engineering Laboratory of Universiti Teknologi PETRONAS, Malaysia.At the other end of the flume, a wave absorber was installed to minimize the reflected during the experiment. The model was held floating by a 4-point taut leg mooring system. The wave profiles in the vicinity of the model were captured by six resistance-type 
wave probes as shown in Figure 2. The three probe method was adopted to obtain the incident and reflected spectral energies at the seaside and leeside of the test model. Calibrations of all the wave probes were carried out with care prior to the experiments so as to ensure the measurement accuracy. The model was also installed with reflective balls for motion tracking purpose. However, the motion responses of the breakwater will not be reported in this paper.
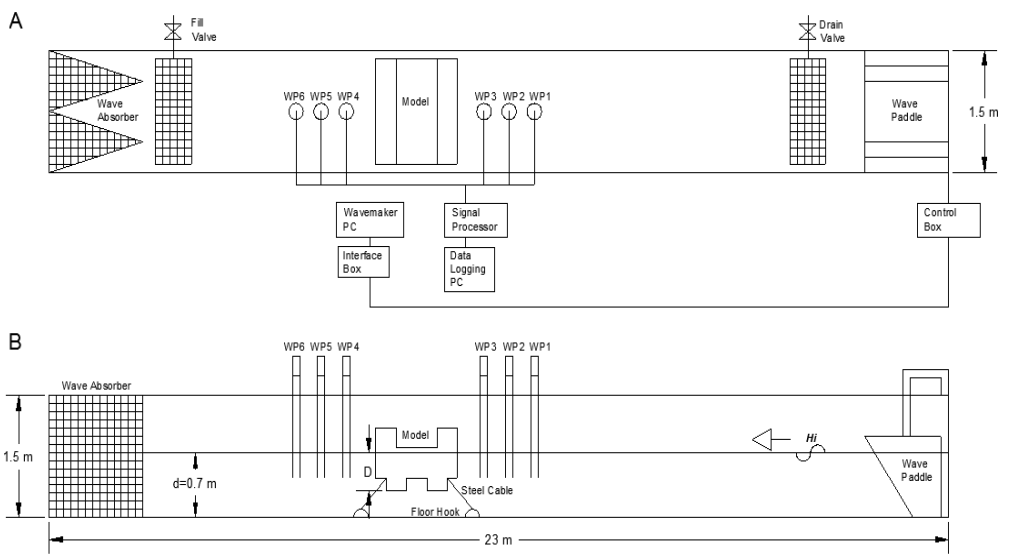

Figure 2: $\quad$ Laboratory set-up: plan view (A); side view (B).

The H-type floating breakwater model was tested in both regular and random sea conditions. Nevertheless, only the result for random seas is addressed herein because the nature of open sea is in random order. The irregularity of the wave pattern was described by JONSWAP spectrum. The model was tested in a water depth, $d$ of $0.7 \mathrm{~m}$ and was subjected to immersion depths, $D$ of $0.08,0.12$ and $0.16 \mathrm{~m}$ from still water level. Correspondingly, this yielded $D / d$ ratio of 0.114 , 0.171 and 0.229 , respectively. The performance of the breakwater was tested by waves of periods $T=0.8,1.0,1.2,1.4 \mathrm{~s}$. The zeroth-moment wave heights, $H_{m 0}$ generated by the wave generator were altered so as to give wave steepness $H_{m 0} / L_{p}$ of 0.04 (mild wave condition), 0.06 (moderate wave condition) and 0.07 (severe wave condition) for each wave period. The test parameters adopted in this experiment are summarized in Table 1.

Table 1: Test parameters.

\begin{tabular}{|l|c|}
\hline Test parameter & \\
\hline Wave type & JONSWAP \\
\hline Peak enhancement factor, $\gamma$ & 3.3 \\
\hline Wave period, $T_{p}(\mathrm{~s})$ & $0.8,1.0,1.2,1.4$ \\
\hline Breakwater draft, $D(\mathrm{~m})$ & $0.08,0.12,0.16$ \\
\hline Water depth, $d(\mathrm{~m})$ & 0.7 \\
\hline Breakwater draft ratio, $D / d$ & $0.1143,0.1714,0.2286$ \\
\hline Wave steepness, $H_{m 0} / L_{p}$ & $0.04,0.06,0.08$ \\
\hline
\end{tabular}




\section{Discussion of results}

Wave transformation around the test model was explored through analysis of the energy density spectra of the measured waves (i.e. incident, reflected and transmitted waves) for each test run. An example of wave energy density spectra for one of the tests in which the breakwater draft ratio $D / d=0.228$, and the incident wave exhibited a peak frequency $f_{p}=1.0 \mathrm{~Hz}$ and wave steepness $H_{m 0, i} / L_{P}=0.04$. Figures 3(a) and 3(b) present the energy spectra for waves that propagate at the front and the leeside of the breakwater, respectively. It is learnt that the reflected wave energy at the seaward of the breakwater is relatively small compared to the energy of incident wave, and that at the leeward of the breakwater is almost inappreciable as most of the wave energy has been dissipated by the wave absorber placed at the end of the wave flume. It is also found that the energy of the transmitted wave is about seven times smaller than that of the incident wave. Therefore, it can be deduced that for this particular test run the H-type floating breakwater has high capability in reducing both the incident and reflected wave heights. This hypothesis has to be ascertained and verified by more experiments conducted under varying wave conditions. The complete results will be deliberated in the subsequent section.

The efficiency of floating breakwaters is measured by transmission coefficient $\left(C_{T}\right)$, reflection coefficient $\left(C_{R}\right)$ and energy dissipation coefficient $\left(C_{L}\right)$ :

$$
\begin{gathered}
C_{T}=\frac{H_{m 0, t}}{H_{m 0, i}} \\
C_{R}=\frac{H_{m 0, r}}{H_{m 0, i}} \\
C_{L}{ }^{2}=1-C_{T}^{2}-C_{R}^{2}=\frac{E_{L}}{E_{i}}
\end{gathered}
$$

where $H_{m 0, i}, H_{m 0, r}$ and $H_{m 0, t}$ are the incident, reflected and transmitted wave heights, respectively, and $E_{i}=$ incident wave energy and $E_{L}=$ energy loss at the breakwater. Derivation of the energy loss $E_{L} / E_{i}$ is presented by Teh et al. [9].

\subsection{Wave transmission}

In this study, the coefficients $C_{T}, C_{R}$ and $C_{L}$ are related with a dimensionless wave parameter $H_{i} / g T^{2}$ where $H_{i}$ is incident wave height, $g$ is the acceleration of gravity and $T$ is the peak period of a wave. This parameter is well accepted as a design parameter for some coastal structures.

Figure 4 presents the $C_{T}$ of the test model subjected to $D / d=0.114,0.171$ and 0.229 . It is seen from the figure that the influence of $H_{i} / g T^{2}$ on $C_{T}$ of $0.114<D / d<$ 0.229 is rather small, and the variability of $C_{T}$ corresponding to $H_{i} / g T^{2}$ increases with an increase of $D / d$. The fluctuation of $C_{T}$ is mainly controlled by the reflectivity of the breakwater (see Figure 5). When the breakwater is immersed with $D / d=0.114$ wave transmission of not more than $63 \%$ is anticipated 

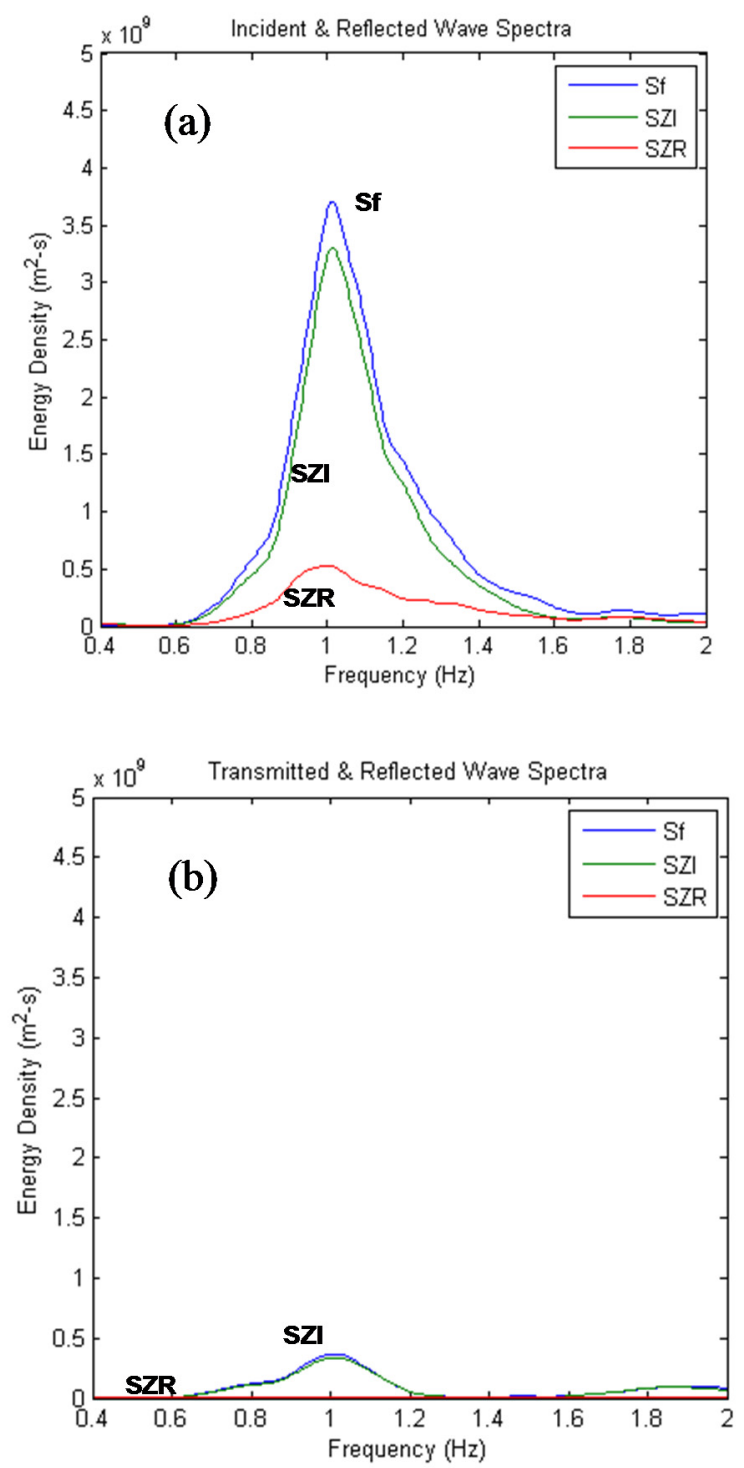

Figure 3: Energy density spectra of the measured incident, reflected and transmitted waves at (a) the front and (b) the leeside of the test model $-D / d=0.228, f_{p}=1.0 \mathrm{~Hz}$ and $H_{m 0, i} / L_{p}=0.04$.

$\left(C_{T}<0.63\right)$. As $D / d$ increases to 0.229 , the lowest $C_{T}$ recorded are about 0.3 at $H_{i} / g T^{2}=0.0070,0.0083$ and 0.0100 . The above results show that the H-type floating breakwater is a good wave attenuator that is capable of suppressing at least $35 \%$ of the height of the incident wave. It is less sensitive to the change of wave condition when the immersion depth is small. 


\section{$C_{T}$ vs $\mathrm{H}_{\mathrm{i}} / \mathrm{gT}^{2}$}

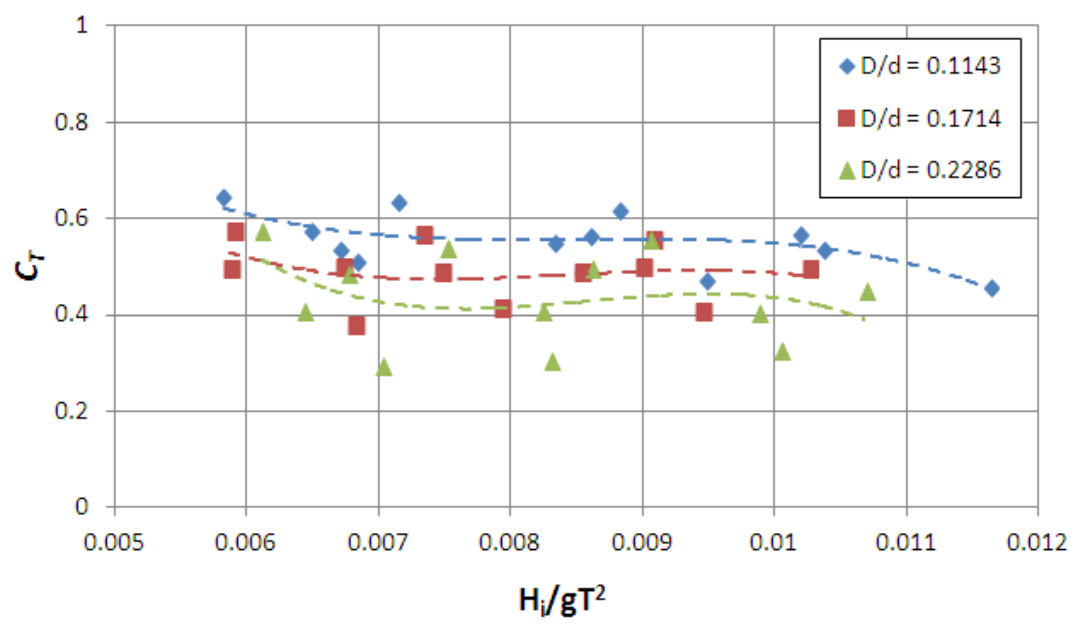

Figure 4: Wave transmission coefficient $C_{T}$.

\subsection{Wave reflection}

The relationship between $C_{R}$ and $H_{i} / g T^{2}$ is demonstrated in Figure 5. No obvious trend can be seen from the best fit plots of $D / d=0.114,0.171$ and 0.229 . This indicates that the waves reflected from the breakwater may not be appreciably affected by the wave steepness. However, the influence of $D / d$ on $C_{R}$ seems to be more dominant in this case. At $D / d=0.114$, the $C_{R}$ data mostly scatter between

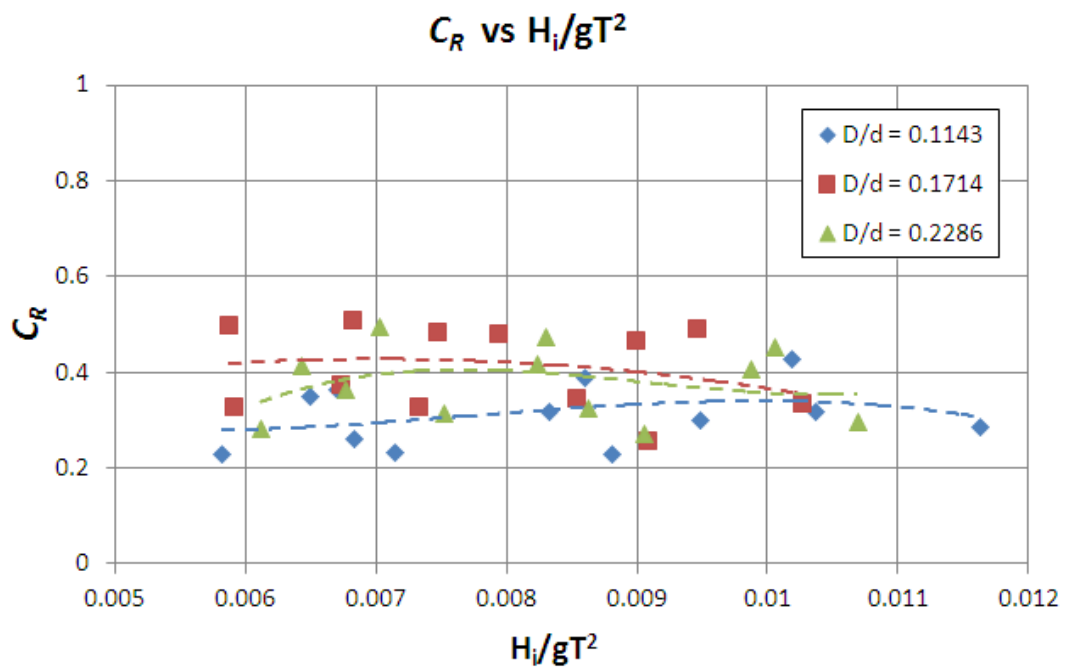

Figure 5: Wave reflection coefficient $C_{R}$. 
0.2 and 0.4 . As for $D / d>0.171$, the $C_{R}$ range slightly increases and the maximum $C_{R}$ recorded is 0.52 . The enhancement of $C_{R}$ is mainly due to increased frontal surface of the breakwater for wave interception as the model is deeply immersed in water. Even so, the amount of energy reflected from the breakwater is considered small (about $25 \%$ of the incident wave energy) as compared to that induced by the vertical surface breakwaters as well as by some of the solid-type floating breakwaters. Hence, the H-type floating breakwater can be considered as a good anti-reflection structure and may be considered suitable to be adopted at sensitive sites.

\subsection{Energy loss}

The amount of energy lost at the breakwater is quantified by $C_{L}^{2}$, which is equivalent to $E_{l} / E_{i}$ as shown in equation (3). Some of the mechanisms that lead to energy loss observed during the experiment are include wave breaking, wave runup and run down, formation of eddies underneath the test model, and generation of sound and heat. Figure 6 presents the $C_{L}{ }^{2}$ of the H-type floating breakwater at $D / d=0.114,0.171$ and 0.228 . A marginal increment of $C_{L}^{2}$ with $H_{i} / g T^{2}$ as shown in the figure indicates that waves of higher steepness tend to dissipate more energy at the breakwater. Breakwater of deeper immersion depth is principally a more efficient energy dissipater due to intense wave interaction with the structure. In general, the H-type floating breakwater of $0.114<D / d<0.228$ can be regarded as a good energy dissipater as it is capable of dissipating $50-70 \%$ of incident wave energy.

\section{$C_{L}^{2}$ vs $\mathrm{H}_{\mathrm{i}} / \mathrm{gT}^{2}$}

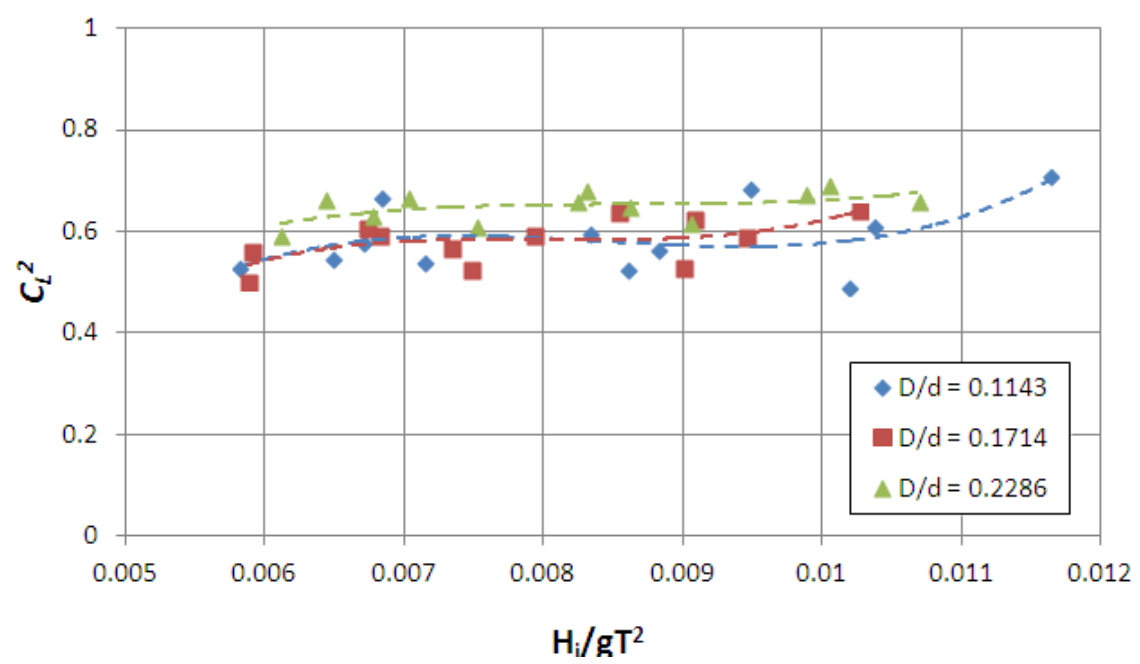

Figure 6: Energy loss coefficient $C_{L}$. 


\section{Conclusion}

A number of experiments were conducted to assess the performance characteristics of the H-type floating breakwater in random waves. The ranges of wave transmission coefficient $C_{T}$, reflection coefficient $C_{R}$ and energy loss $C_{L}{ }^{2}$ of the H-type floating breakwater are summarized in Table 2 . Wave transmissibility and reflectivity of the breakwater were controlled by the relative immersion depth of the breakwater $D / d$, and the energy loss characteristics were governed by both wave parameter $H_{i} / g T^{2}$ and $D / d$. Breakwaters of deeper immersion depth was proven to be an effective wave attenuator, a good anti-reflection structure and an efficient energy dissipater.

Table 2: $\quad$ Ranges of $C_{T}, C_{R}$ and $C_{L}^{2}$ at $D / d=0.114,0.171$ and 0.228 .

\begin{tabular}{|c|c|c|c|}
\hline$D / d$ & 0.113 & 0.171 & 0.228 \\
\hline$C_{T}$ & $0.45-0.64$ & $0.38-0.57$ & $0.29-0.57$ \\
\hline$C_{R}$ & $0.23-0.43$ & $0.25-0.51$ & $0.27-0.49$ \\
\hline$C_{L}{ }^{2}$ & $0.49-0.70$ & $0.50-0.64$ & $0.58-0.68$ \\
\hline
\end{tabular}

\section{Acknowledgements}

This research was made possible with kind support of YUTP Fundamental Research Grant. The authors wish to thank Miss Nor Nadia Aida binti Mahadi for her help in conducting laboratory experiments.

\section{References}

[1] Allsop, N.W.H., Vertical walls and breakwaters: Optimisation to improve vessel safety and wave disturbance by reducing wave reflections. In Wave Forces on Inclined and Vertical Wall Structures, American Society of Civil Engineers: New York, pp. 232-258, 1995.

[2] Wang, H.Y., \& Sun, Z.C., Experimental study of a porous floating breakwater, Ocean Engineering, 37, pp. 520-527, 2010.

[3] Koutandos, E.V. \& Prinos, P.E., Hydrodynamic characteristics of semiimmersed breakwater with an attached porous plate, Ocean Engineering, 38, pp. 34-48, 2011.

[4] He, F., Huang Z. \& Law, W.K., Hydrodynamic performance of a rectangular floating breakwater with and without pneumatic chambers: An experimental study, Ocean Engineering, 51, pp. 16-27, 2012.

[5] McCartney, B.L., Floating breakwater design, Waterway, Port, Coastal and Ocean Engineering, 111, pp. 304-317, 1985.

[6] Teh, H.M., Hydraulic performance of free surface breakwaters: A review, Sains Malaysian, 42(9), pp.1301-1310, 2013. 
[7] Hsu, H.H. \& Wu, Y.C., Scattering of water wave by a submerged horizontal plate and a submerged permeable breakwater. Ocean Engineering, 26(4), pp. 325-341, 1999.

[8] $\mathrm{Hu}, \mathrm{H} .$, Wang, K.H. and Williams, A.N., Wave motion over a breakwater system of a horizontal plate and a vertical porous wall. Ocean Engineering, 29(4), pp. 373-386, 2002.

[9] Teh, H.M., Venugopal, V. and Bruce, T., Hydrodynamic characteristics of a free surface semicircular breakwater exposed to irregular waves. Journal of Waterway, Port, Coastal and Ocean Engineering, 138(2), pp. 149-163, 2012. 